\title{
Cost effectiveness of detecting Barrett's cancer
}

T A Wright, M R Gray, A I Morris, I T Gilmore, A Ellis, H L Smart, M Myskow, J Nash, R J Donnelly, A N Kingsnorth

\begin{abstract}
Background-Screening Barrett's oesophagus is controversial owing to a large variation in the reported incidence of neoplastic change and lack of evidence that screening improves tumour prognosis. Aims-To determine the incidence of Barrett's cancer, its cost of detection, and stage of disease at time of diagnosis.

Patients and Methods-Data from our surveillance programme have been reviewed to assess the incidence of malignant change, tumour stage at diagnosis, and the cost per cancer detected.

Results-166 patients had annual endoscopic surveillance. Six patients (five men) developed cancer - an incidence of one cancer per 59 male and 167 female patient-years of follow up. The screened group had a significantly earlier stage than a control group of unscreened cancers $(p<0.05)$. The cost of detecting one cancer was $£ 14868$ for men and $£ 42084$ for women.
\end{abstract}

Conclusions-The cost of screening for Barrett's cancer is high but may be justified on the basis of the high incidence of detecting early stage disease.

(Gut 1996; 39: 574-579)

Keywords: Barrett oesophagus, cost-benefit analysis, cost effectiveness, oesophageal neoplasms, precancerous conditions.

Departments of

Surgery, Pathology, and Gastroenterology, Royal Liverpool Hospital, Liverpool

T A Wright

M R Gray

A I Morris

I T Gilmore

J Nash

A N Kingsnorth

Departments of

Gastroenterology,

Pathology, and

Cardiothoracic

Surgery, Broadgreen

Hospital, Liverpool

A Ellis

H L Smart

M Myskow

R J Donnelly

Correspondence to:

Mr T A Wright,

Surgical Registrar,

Pinderfields General

Hospital, Wakefield,

West Yorkshire.

Accepted for publication

30 May 1996
Barrett's oesophagus is a common acquired condition that predisposes to development of adenocarcinoma of the oesophagus. ${ }^{1}$ It is usually related to acid reflux. ${ }^{2}$ About $10 \%$ of patients having endoscopy for reflux symptoms will have Barrett's oesophagus. ${ }^{3}$ Necropsy series suggest that $1 \%$ of the adult population develop Barrett's oesophagus. ${ }^{4}$

The relative risk of developing cancer with Barrett's oesophagus is difficult to measure. Prevalence rates of Barrett's cancer in the surgical literature that range from 10 to $46 \%{ }^{15}$ are gross overestimates of its true prevalence because benign disease tends to be asymptomatic. ${ }^{6}$ Only one case in 20 is detected in life. ${ }^{4}$ The most accurate method of measuring the risk of Barrett's cancer is therefore its incidence. Prospective endoscopic surveillance programmes provide the most accurate means of measuring the incidence, which has been estimated to be on average one cancer per 76 (range 48-175) patient-years of surveillance ${ }^{7}$ (Table I).
Over the past decade, adenocarcinoma of the oesophagus has been increasing in contrast with a slight decline in the incidence of squamous cell carcinoma. ${ }^{19} 20$ This may explain why the incidence of Barrett's cancer tends to be lower in the earlier reports in Table I. It is estimated that $64-86 \%$ of all adenocarcinomas of the oesophagus originate from Barrett's epithelium. ${ }^{21}{ }^{22}$ Short segment metaplasia may account for a large proportion of the remainder. ${ }^{23}$

Screening for adenocarcinoma in Barrett's oesophagus has been advocated with the aim of identifying early asymptomatic cancer. ${ }^{24}$ Dysplasia often progresses from low to high grade and is still the most effective way of identifying those at highest risk of malignancy. ${ }^{25}$ High grade dysplasia is associated with early invasive malignancy in $50-66 \%$ of cases and is considered by some surgeons to be an indication for surgery. ${ }^{26}{ }^{27}$ Resection of early stage adenocarcinoma or high grade dysplasia is associated with prolonged survival. ${ }^{28} \mathrm{By}$ contrast, lymph node positive disease is often not resectable, and resected cases have a low cure rate. ${ }^{29}$

Despite this, endoscopic surveillance is not universally undertaken. The reasons for this probably include cost factors, but also uncertainty about the 'pick-up' or case detection rate in an already elderly population. Furthermore, and in the current climate of evidence-based medicine, the proof that screen detected cancers have a better prognosis than those which have not been under surveillance is still lacking.

We have evaluated our experience of screening for Barrett's cancer. The aims were to determine the incidence of Barrett's cancer, to evaluate the effectiveness of surveillance in detecting curable, early stage cancers, and to estimate the case detection cost.

TABLE I Reported incidence of Barrett's cancer

\begin{tabular}{|c|c|c|c|}
\hline Report & $\begin{array}{l}\text { No of } \\
\text { patient- } \\
\text { years }\end{array}$ & $\begin{array}{l}\text { No of } \\
\text { cancers }\end{array}$ & $\begin{array}{l}\text { Incidence (per } \\
\text { patient-year) }\end{array}$ \\
\hline $\begin{array}{l}\text { Spechler } 1984^{8} \\
\text { Sprung } 1984^{9} \\
\text { Cameron } 1985^{10} \\
\text { Sampliner } 1985^{11} \\
\text { Achkar } 1988^{12} \\
\text { Robertson } 1988^{13} \\
\text { Van Der Veen } 1989^{14} \\
\text { Ovaska } 1989^{15} \\
\text { Hameeteman } 1989^{16} \\
\text { Skinner } 1989^{17} \\
\text { Williamson } 1991^{18}\end{array}$ & $\begin{array}{r}350 \\
162 \\
884 \\
92 \\
166 \\
218 \\
681 \\
166 \\
269 \\
145 \\
497\end{array}$ & $\begin{array}{l}2 \\
2 \\
2 \\
1 \\
1 \\
3 \\
4 \\
3 \\
5 \\
3 \\
5\end{array}$ & $\begin{array}{l}1 \text { in } 175 \\
1 \text { in } 81 \\
1 \text { in } 441 \\
1 \text { in } 92 \\
1 \text { in } 166 \\
1 \text { in } 56 \\
1 \text { in } 170 \\
1 \text { in } 55 \\
1 \text { in } 52 \\
1 \text { in } 48 \\
1 \text { in } 99\end{array}$ \\
\hline
\end{tabular}

^Postal questionnaire; all other reports are endoscopic surveillance. 


\section{Methods}

\section{Patients}

The databases of the gastrointestinal units at the Royal Liverpool and Broadgreen Hospitals were used to identify all patients with an endoscopic diagnosis of Barrett's oesophagus over a 12 year period between 1981 and 1992 . Cross referencing with the pathological

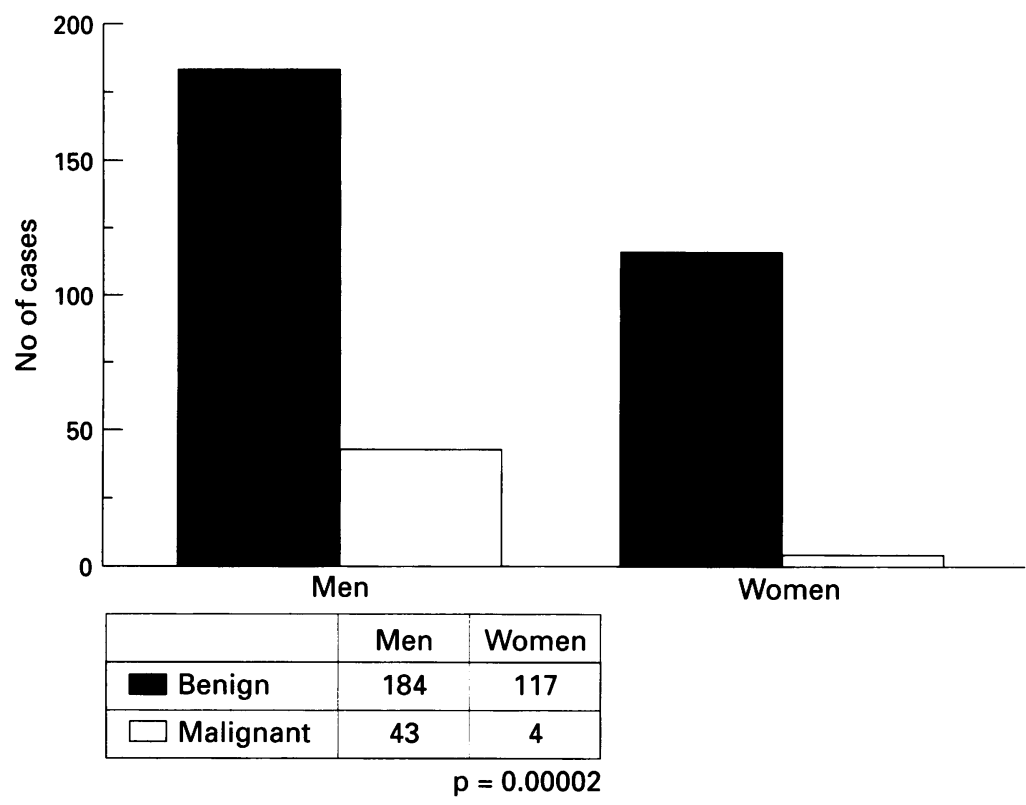

Figure 1: Sex distribution of all patients with a histological diagnosis of Barrett's oesophagus at initial endoscopy - benign and malignant.

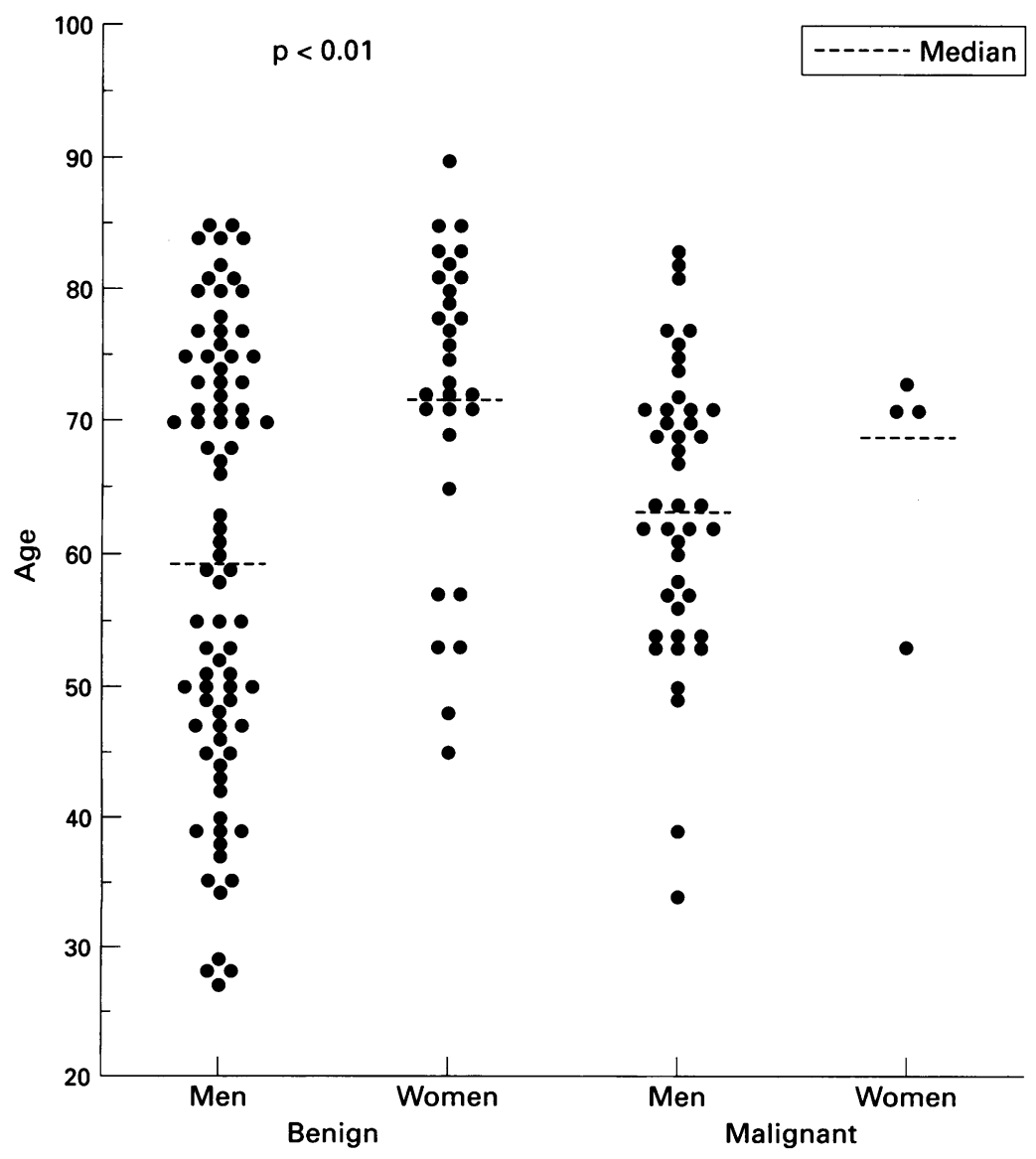

Figure 2: Age distribution of all patients with a histological diagnosis of Barrett's oesophagus. databases was then used to obtain histological confirmation of a columnar lined (Barrett's) oesophagus. Barrett's oesophagus was defined as columnar epithelium in biopsy specimens taken either at least $3 \mathrm{~cm}$ proximal to the gastro-oesophageal junction, or $0-3 \mathrm{~cm}$ from the gastro-oesophageal junction but showing intestinal metaplasia. The latter represents a short segment Barrett's oesophagus, which is known to have a significant risk of malignant change. $^{21} 23$ The gastro-oesophageal junction was defined to be where the saccular stomach and gastric folds end and the tubular and smoother oesophagus begins. Cases not fulfilling these criteria were excluded.

\section{Methods}

Patient details, extent of Barrett's oesophagus, duration of endoscopic surveillance, and eventual outcome were all noted. Over a similar time period, patients presenting de novo with adenocarcinomas of the oesophagus arising in Barrett's epithelium were used to act as a control group. Patients who had suspicious symptoms or endoscopic signs of cancer at presentation and who were confirmed as having a Barrett's cancer within a year were not regarded as having screen detected cancers. Only those tumours that had been resected were used in the comparison, resulting in accurate staging in both groups but at the risk of reducing the impact of screening by excluding unresectable stage III and IV disease in the control group. The International Union Against Cancer TNM classification of malignant tumours was used to stage the oesophageal cancers. ${ }^{30}$

The calculation of the cost of surveillance was made on the basis that the average patient had annual endoscopy at which two biopsy specimens were taken and a single outpatient visit.

Statistical techniques used included MannWhitney $U$ test, Poisson interval tests, and Yates's corrected $\chi^{2}$ test as appropriate.

\section{Results}

Age and sex

Barrett's oesophagus was identified in 348 patients. Of these, 47 patients also had adenocarcinoma present. As shown in Figure 1, 61\% of the benign cases were men, whereas $91 \%$ of the malignant cases were men $\left(\mathrm{p}<0.005, \chi^{2}\right.$ test).

In Figure 2, men with benign disease had a bimodal distribution with median age of 58.5 (range 27-84); and women had a unimodal distribution with a median age of 73 (range 35-92) $(p<0.05)$. The average age of male $(66$ years, range 34-92) and female (71 years, range 53-73) patients with tumours did not differ from those with metaplasia without malignant change.

\section{Surveillance data}

Only 166 of the 301 patients $(55 \%)$ with no evidence of cancer at presentation entered the 


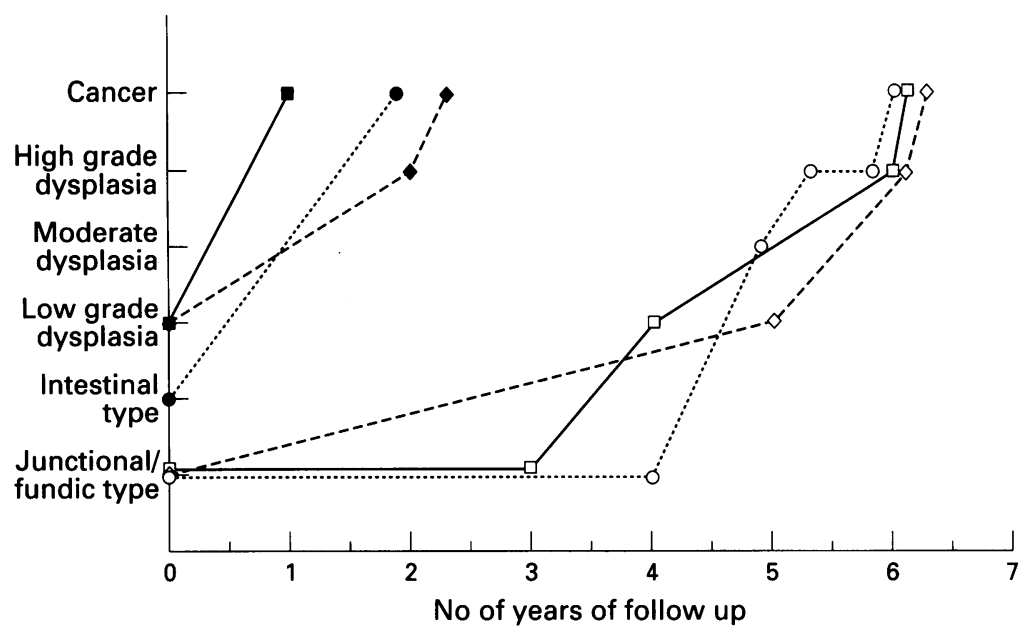

Figure 3: Histological progression to malignancy in the six screen detected tumours.

prospective surveillance programme. Of those patients who were not screened, 79 were excluded because they were unfit for major surgery; 52 were excluded either by consultants who did not routinely screen Barrett's oesophagus or by errors in follow up and only three patients actually refused endoscopic surveillance. One hundred and eight $(65 \%)$ male and $58(35 \%)$ female patients who entered the surveillance programme were screened for a total of 294 and 167 patientyears, respectively. Most patients were, in fact, recruited in the past five years as the importance of Barrett's oesophagus as a premalignant condition has made endoscopists more vigilant in looking for its presence. Many patients were elderly and died of unrelated causes or were subsequently excluded because they had become unfit for surgery. This explains why, in a 12 year surveillance programme, the mean length of follow up was only 2.7 years for men and 2.9 years for women.

Adenocarcinoma of the oesophagus developed in five men and one woman. The histological progression to cancer is shown in Figure 3. One of these six patients had developed dysphagia, the other five having no significant symptoms that would have normally warranted endoscopy. The incidence or risk of developing cancer was one cancer detected per 59 male or 167 female patient-years of surveillance. Not included are four other patients who had oesophagectomies after screening had discovered high grade dysplasia on random biopsies. Owing to practical difficulties, we have not looked to see if any of the nonscreened patients developed Barrett's cancer.

Comparison of screened and unscreened cancers All six patients with screen detected cancers had oesophagogastrectomy. Table II shows the stage of disease in the screened group after resection compared with 25 unscreened consecutively resected group of patients with Barrett's cancers. There were no sex differences between the two groups. The mean age of the surveillance detected cancers was $67 \cdot 5$ compared with $62 \cdot 6$ for the unscreened group
TABLE II Stage of cancer after resection in the screened and unscreened groups. Node negative versus node positive $(p=0 \cdot 2$ Fisher's exact test)

\begin{tabular}{|c|c|c|}
\hline Stage & Unscreened & Screened \\
\hline $\begin{array}{l}0 \\
\text { I } \\
\text { IIA }\end{array}$ & $\begin{array}{r}1 \\
0 \\
11\end{array}$ & $\left.\begin{array}{l}1 \\
2 \\
2\end{array}\right\}$ Lymph node negative \\
\hline $\begin{array}{l}\text { IIB } \\
\text { III } \\
\text { IV }\end{array}$ & $\begin{array}{l}3 \\
3 \\
7\end{array}$ & $\left.\begin{array}{l}0 \\
1 \\
0\end{array}\right\}$ Lymph node positive \\
\hline Total & 25 & 6 \\
\hline
\end{tabular}

( $p=0.05$ Mann-Whitney $U$ test). However, there was no difference in ages between those who did not develop cancer in the surveillance group and the unscreened cancer group. According to the UICC classification of disease, stage 0 is defined as carcinoma in situ. This was recorded for two patients (one screened and one unscreened) who had unequivocal invasive cancer on preoperative endoscopic biopsy but, at most, had high grade dysplasia or carcinoma in situ in the resection specimen. Both these patients had had preoperative chemotherapy as part of a national trial.

An important finding from this study was that surveillance detected cancers were more likely to be node negative than unscreened cancers. Unfortunately, by excluding unresectable advanced stage tumours from the control group, this did not quite reach statistical significance.

The cost of an endoscopy in 1992 was $£ 80$ according to the financial department at the Royal Liverpool Hospital, with biopsies there is an additional cost of $£ 40$ and an outpatient visit is an extra $£ 60$ - a total of $£ 180$ per endoscopy. The 166 screened patients had a total of 653 endoscopies in 461 patient years of surveillance - an average of 1.4 endoscopies per patient per year. Thus the screening cost per patient per year is $1.4 \times 180=£ 252$. From the incidence data the cost of detecting a single cancer in a male patient is $59 \times 252=£ 14868$ and in a woman is $167 \times 252=£ 42084$.

\section{Discussion}

\section{Risk factors - age and sex}

Male sex has been confirmed to be associated with higher cancer risk. While the male to female ratio of patients with metaplasia is generally about $3: 2,{ }^{6} 1218$ the ratio in patients with Barrett cancers ranges from 5:1 to 29: $1^{5} 1131-10: 1$ being about average. Previous series suggest that this effect is determined by heavy smoking and alcohol consumption in the male patients; malignant change is associated with a significant smoking history in over $90 \%$ of cases. $^{832}$

We noticed a bimodal age distribution for men with benign Barrett's oesophagus. Young men who presented with symptoms in their $20 \mathrm{~s}$ and 30s may represent a childhood Barrett's subgroup, which has been shown to be much more common in boys than girls. ${ }^{33}$ Borrie and Goldwater also noticed this bimodal distri- 
bution and proposed a double aetiology for Barrett's oesophagus. ${ }^{34}$ Our data support this view.

There are reports of adenocarcinomas occurring in patients with Barrett's oesophagus as young as 11 - a fact which has led to the recommendation of surveillance from the age of $10 .^{35}$ We excluded children from our study, and the youngest patient with Barrett's cancer was a man aged 34, so we agree that young men with Barrett's oesophagus represent a subgroup who should be considered at high risk and should benefit the most from endoscopic surveillance.

\section{Previous surgery}

Antireflux surgery is known not to be protective against subsequent development of malignancy as there are now numerous reports of cancers occurring many years after successful surgery. ${ }^{14}$ 36-38 One of our screen detected cancers had also developed 12 years after having a symptomatically successful antireflux procedure, suggesting that malignant change is independent of continued gastrooesophageal reflux (acid or alkaline). Complete regression of Barrett's oesophagus after surgical or medical treatment is rare and the presence of unknown co-carcinogens means that continued surveillance is necessary.

It is of interest that one of our patients had had a previous polyagastrectomy for peptic ulceration 10 years before the development of his screen detected cancer. Biliary reflux may have been an important factor in the cause of cancer in this case. Others have also noticed previous gastric surgery to be common in patients presenting with Barrett's cancer. ${ }^{10} 14$

\section{Interval cancers}

Interval cancers are possible and may prove to be of a more aggressive type than one presenting with a more insidious onset. One of our screen detected cancers had symptoms suggestive of cancer before endoscopic diagnosis. He had decided to wait for his annual endoscopy before seeking attention and after resection was found to have a stage III tumour. The patient's previous screening endoscopy was performed before the introduction of four quadrant biopsies at two centimetres of Barrett's epithelium as recommended previously. ${ }^{24}$ It is possible that had he had more detailed sampling, dysplasia might have been detected and early signs of malignant change acted upon before lymph node metastases developed. We are currently recommending that patients with low and moderate grade dysplasia be rebiopsied after three months of treatment with a proton pump inhibitor. ${ }^{39}$ This sampling method has also been used so that even patients with high grade dysplasia have been safely followed up for up to nine years. ${ }^{4041}$

In a recent report on the cost effectiveness of screening for Barrett's cancer, ${ }^{42}$ assumptions about incidence and natural history of Barrett's cancer were made. Their decision making analysis recommends surveillance every three, four, or even five years. This is based on the assumption that unscreened cancers have a resection rate of $49 \%$ - which seems very high, and a resection rate of only $75 \%$ for screened cancers - which is much lower than our $100 \%$ resection rate. Of more importance is that they assume only a $64 \%$ five year survival for screen detected cancers. As we have already pointed out, there are no data to support this assumption. Finally, they assume that cancer develops over four to five years but in $50 \%$ of our cases, cancer was detected after fewer than two years (Fig 3). A screening strategy of endoscopy every three or more years is therefore likely to increase the number of interval cancers.

\section{Cost effectiveness analysis}

Our study has shown an incidence of malignant change in Barrett's oesophagus that is of a similar order of magnitude to that in the previously reported series (Table I). Our incidence was 2.8 times higher for men. In the above mentioned series, the number of cancers detected has never been greater than five and many detected only two or three cases. The $95 \%$ confidence limits for the actual incidence will therefore vary enormously. We detected six cases of Barrett's cancer and our 95\% confidence limits for incidence are also quite wide, ranging from 1:25 to $1: 181$ for men and $1: 30$ to $1: 6600$ (Poisson distribution). ${ }^{43}$

Case detection cost is dependent on the incidence of malignant change in the screened group. ${ }^{42}$ Our costings are based on the observed incidence and estimated values for the cost of endoscopy, biopsy, and an outpatient visit. In a previous study by Achkar and Carey in 1988 case detection cost was estimated to be $\$ 62000 .^{12}$ Their calculation is based on the detection of a single cancer occurring during a 31 month follow up of a very small group of patients. As we have shown with our figures, the confidence limits for this figure will have such a wide range that this case detection cost may not be very accurate. Indeed, by combining our data with all the other reported screen detected cancers, we have calculated a mean incidence of $1: 75$ with $95 \%$ confidence intervals of $1: 55$ to $1: 112$ (Poisson distribution) ${ }^{43}$ (We excluded three studies because they were conducted by postal questionnaire and may have firstly, overdiagnosed Barrett's oesophagus - which is common in our experience - and secondly, missed early asymptomatic tumours, both of which tend to underestimate the true incidence. ${ }^{81014}$ ) The combined $95 \%$ confidence interval of case detection costs are therefore between $55 \times 252=£ 13860$ and $11 \times 2252=£ 28224$. It is recognised that our estimated figures may be very different from the costs in other units around the country.

Our figure of $£ 14868$ per male cancer detected is similar to the $£ 12000$ figure from Nottingham ${ }^{7}$ and is in the more cost effective end of this range. This figure may be even lower as four men in the surveillance group had 
surgery for high grade dysplasia before they progressed any further and were therefore not classified as screen detected cancers. The estimated cost of detecting a female cancer still compares favourably with the costs of screening for other malignancies. For example, when faecal occult blood testing is used the cost per life saved from colorectal cancer is $\$ 225000,{ }^{44}$ and mammography for breast cancer has been estimated to cost up to £1000 000. ${ }^{45}$

Cost effectiveness analysis needs to take into account many factors other than incidence and stage at time of detection. Screening should only be contemplated in patients who are potentially fit for oesophageal resection. In the elderly population the potential increase in life expectancy by detecting early oesophageal cancer is limited. In terms of life-years gained there will be a less favourable comparison with other cancers such as colorectal and breast cancer which often develop at a younger age. Money spent on screening, however, may be partially offset against savings of the high cost of adjuvant and palliative treatments required in more advanced cases. Recent research aimed at identifying those at particularly high risk may ultimately help to reduce costs. ${ }^{46}$

We have shown that screening is effective in identifying tumours at a curable stage. We would like to emphasise that unresectable advanced tumours were not included in the control group because they cannot be accurately staged. Their inclusion would have increased the strength of our statistical analysis. All five of our asymptomatic Barrett's cancers were node negative and had potentially curative resections. We believe that there has only been one other report comparing stage of disease between a screened and unscreened group of Barrett's cancers. ${ }^{36}$ In this report the screened group also had better stage of disease compared with the unscreened group $(p=0.006)$.

In conclusion, screening should only be contemplated in the younger patients who are potentially fit for oesophageal resection. In our experience, only patients with the intestinal type of metaplasia are at risk of dysplasia and cancer and all others should not be screened. Successful medical or surgical treatment of gastro-oesophageal reflux disease should not necessarily exclude patients from a surveillance programme. Regular endoscopic surveillance of high risk groups will be more cost effective. These include the male sex, those with established dysplasia of any grade, and may include patients who smoke heavily, develop Barrett's oesophagus at a young age, have had previous gastric surgery, or have long segment disease.

It is clear that although this is one of the largest studies of this type, the numbers of screen detected cancers are still very low. Large multicentred prospective surveillance programmes are required to determine accurately the cost per life year saved.

Mr T A Wright was supported by the North West Cancer Research Fund. Data previously published in abstract format and presented to the British Society of Gastroenterology, September 1993 .
1 Naef AP, Savary M, Ozzello L. Columnar-lined lower esophagus:an acquired lesion with malignant predisposition. Report on 140 cases of Barrett's esophagus with 12 adenocarcinomas. $₹$ Thorac Cardiovasc Surg 1975; 70: 826-35.

2 Iascone C, DeMeester TR, Little AG, Skinner DB. Barrett's esophagus: functional assessment, proposed pathogenesis and surgical therapy. Arch Surg 1983; 118: 543-9.

3 Winters C, Spurling TJ, Chobanian SJ, Curtis D, Esposito RL, Hacker JF, et al. Barrett's esophagus: a prevalent, RL, Hacker JF, et al. Barrett's esophagus. a prevalent, Gastroenterology 1987; 92: 118-24.

Gastroenterology 1987; 92: 118-24.
4 Cameron AJ, Zinsmeister AR, Ballard DJ, Carney JA. Prevalence of columnar-lined (Barrett's) esophagus. Comparison of population-based clinical and autopsy Comparison of population-based clinical

5 Skinner DB, Walther BC, Riddell RH, Schmidt H, Iascone C, DeMeester TR. Barrett's esophagus. Comparison of benign and malignant cases. Ann Surg 1983; 198: 554-66.

6 Cooper BT, Barbezat GO. Barrett's oesophagus: a clinical study of 52 patients. $Q \mathcal{F}$ Med 1987; 238: 98-108.

7 Atkinson M, Iftikhar SY, James PD, Robertson CS, Steele RJC. The early diagnosis of oesophageal adenocarcinoma by endoscopic screening. Eur $\mathcal{f}$ Cancer Prev 1992; 1: by endosco.

8 Spechler SJ, Robbins AH, Bloomfield R, Vincent ME, Heeren T, Doos WG, et al. Adenocarcinoma and Barrett's esophagus. An overrated risk? Gastroenterology Barrett's esophag

9 Sprung DJ, Ellis FH, Gibb SP. Incidence of adenocarcinoma in Barrett's esophagus (abstract). $A m \mathcal{F}$ Gastroenterol 1984; 79: 817

10 Cameron AJ, Ott BJ, Payne WS. The incidence of adenocarcinoma in columnar-lined (Barrett's) esophagus. $N$ Engl F Med 1985; 313(14): 857-9.

11 Sampliner RE, Kogan FJ, Morgan TR, Tripp M. Progression-regression of Barrett's esophagus (abstract). Gastroenterology 1985; 88: 1567.

12 Achkar E, Carey W. The cost of surveillance for adenocarcinoma complicating Barrett's esophagus. $A m$ Gastroenterol 1988; 83: 291-4.

13 Robertson CS, Mayberry JF, Nicholson DA, James PD, Atkinson $M$. Value of endoscopic surveillance in the detection of neoplastic change in Barrett's oesophagus. $B$ f Surg 1988; 75: 760-3.

14 Van Der Veen $\mathrm{AH}$, Dees J, Blankenstein JD, Van Blankenstein M. Adenocarcinoma in Barrett's oesophagus: an overrated risk. Gut 1989; 30: 14-18.

15 Ovaska J, Miettinen M, Kivilaakso E. Adenocarcinoma in Barrett's esophagus. Dig Dis Sci 1989; 34: 1336-9.

16 Hameeteman W, Tytgat GNJ, Houthoff HJ, Van Den Tweel JG. Barrett's esophagus: Development of dysplasia and JG. Barrett's esophagus: Development of dysplasia and

adenocarcinoma. Gastroenterology $1989 ; 96: 1249-56$.
Skinner DB. The incidence of cancer in Barrett's esophagus varies according to series. In: Giuli R, McCallum RW, varies Benign lesions of the esophagus and cancer. New York, NY: Springer-Verlag, 1989: 764-5

18 Williamson WA, Ellis FH, Gibb SP, Shahian DM, Aretz HT, Heatley GJ, et al. Barrett's esophagus. Prevalence and incidence of adenocarcinoma. Arch Intern Med 1991 151: 2212-16.

19 Blot WJ, Devesa SS, Kneller RW, Fraumeni JF. Rising incidence of adenocarcinoma of the esophagus and gastric cardia. $\mathcal{F} A M A$ 1991; 265: 1287-9.

20 Pera M, Cameron AJ, Traskek VF, Carpenter HA, Zinsmeister AR. Increasing incidence of adenocarcinoma of the esophagus and esophagogastric junction. Gastroof the esophagus and esopha
enterology 1993; 104: 510-13.

21 Hamilton SR, Smith RRL, Cameron JL. Prevalence and characteristics of Barrett esophagus in patients with adenocarcinoma of the esophagus and esophagogastric junction. Hum Pathol 1988; 19: 942-8.

22 Haggitt RC, Tryzelaar J, Ellis FH, Colcher H. Adenocarcinoma complicating columnar epithelium-lined (Barrett's) esophagus. Am f Clin Pathol 1978; 70: 1-5.

23 Schnell TG, Sontag SJ, Chejfec G. Adenocarcinomas arising in short segments of Barrett's esophagus. Dig Dis Sci 1992; 37: 137-43.

24 Dent J, Bremner CG, Collen MJ, Haggitt RC, Spechler SJ. Working party report to the world congresses of Working party report to the world congresses of Gastroenterol Hepatol 1991; 6: 1-22.

25 Reid BJ, Weinstein WM, Lewin KJ Haggitt RC VanDeventer G, DenBesten L, et al. Endoscopic biopsy can detect high-grade dysplasia or early adenocarcinoma in a Barrett's esophagus without grossly recognizable neoplastic lesions. Gastroenterology 1988; 94: 81-90.

26 Pera M, Trastek VF, Carpenter HA, Allen MS, Deschamp C, Pairolero PC. Barrett's esophagus with high-grade dysplasia: an indication for esophagectomy? Ann Thorac Surg 1992; 54: 199-204.

27 Hamilton SR, Smith RRL. The relationship between columnar epithelial dysplasia and invasive adenocarcinoma arising in Barrett's esophagus. Am 7 Clin Pathol 1987; 87: 301-12.

28 Rusch VW, Levine DS, Haggitt R, Reid BJ. The management of high grade dysplasia and early cancer in marrett's esophagus. Cancer 1994; 74: 1225-9.

29 Thomas RIS, Mullerworth MW, Bhathal PS, Gregory PJ StJohn DJB. Results of surgery as the first treatment for StJohn DJB. Results of surgery as the first treatment for
oesophageal cancer - a hospital based prospective study. oesophageal cancer - a hospit
Dis Esoph 1994; 7: 179-83.

30 UICC International Union Against Cancer. Hermanek P, Sobin LH, eds. TNM classification of malignant tumours. 4th ed. Berlin: Springer-Verlag, 1987. 
31 Sanfey H, Hamilton SR, Smith RRL, Cameron JL. Carcinoma arising in Barrett's esophagus. Surg Gynecol Obstet 1985; 161: 570-4.

32 Gray MR, Donnelly RJ, Kingsnorth AN. The role of smoking and alcohol in metaplasia and cancer risk in Barrett's columnar lined oesophagus. Gut 1993; 34: 727-31.

33 Hassall E. Barrett's esophagus: new definitions and approaches in children. $\mathcal{F}$ Pediatr Gastroenterol Nutr 1993; 16: 345-64.

34 Borrie J, Goldwater L. Columnar cell-lined esophagus: Assessment of etiology and treatment. A 22 year Assessment of etiology and treatment. A 22 year
experience. 7 Thorac Cardiovasc Surg 1976; 7: 825-34.

35 Hassall E, Dimmick JE, Magee JF. Adenocarcinoma in childhood Barrett's esophagus. Case documentation and the need for surveillance in children. $A m \mathcal{F}$ Gastroenterol 1993; 88: 282-8.

36 Streitz JM, Andrews CW, Ellis FH. Endoscopic surveillance of Barrett's esophagus. Does it help? $\mathcal{F}$ Thorac Cardiovas Surg 1993; 105: 383-8.

37 Hamilton SR, Hutcheon DF, Ravich WJ, Cameron JL Paulson M. Adenocarcinoma in Barrett's esophagus after elimination of gastroesophageal reflux. Gastroenterology 1984; 86: 356-60.

38 Rosenberg JC, Budev H, Edwards RC, Singal S, Steiger Z, Sundareson AS. Analysis of adenocarcinoma in Barrett's esophagus utilizing a staging system. Cancer 1985; 55: 1353-60.

39 Gray MR, Kingsnorth AN. Barrett's oesophagus and other ulcerative complications of gastro-oesophageal reflux. Gullet 1993; 3: 42-52.

40 Levine DS, Haggitt RC, Blount PL, Rabinovitch PS, Rusch VW, Reid BJ. An endoscopic biopsy protocol can differentiate high-grade differentiate high-grade dysplasia from early adenocarcinoma

41 Wright TA, Myscow MW, Nash J, Gray MR, Kingsnorth AN. High grade dysplasia in Barrett's oesophagus - How AN. High grade dysplasia in Barrett's oesophagus -
should it be managed? Gut 1994; 35(suppl 2): S22.

42 Provenzale D, Kemp JA, Arora S, Wong JB. A guide for surveillance of patients with Barrett's esophagus. $A m \mathfrak{F}$ Gastroenterol 1994; 89: 670-80.

43 Lentner C, ed. Geigi scientific tables. Vol 2. Introduction to statistics, statistical tables, mathematical formulae. Basle, Switzerland: Ciba Geigy, 1982.

44 Lieberman DA. Cost-effectiveness model for colon cancer screening. Gastroenterology 1995; 109: 1781-90.

45 Baum M. Screening for breast cancer, time to think - and stop? Lancet 1995; 346: 436(letter).

46 Wright TA, Kingsnorth AN. Barrett's oesophagus and markers of malignant potential. Eur f Gastroenterol Hepatol 1994; 6: 656-62. 